\title{
ANTIBIOTIC SENSITIVITY OF TRUE AND OPPORTUNISTIC PATHOGENS IN DENTAL UNIT WATER LINES
}

\author{
H. I. INABO; D. O. TORYILA AND F. A. ANTHONY
}

(Received 16, August 2008; Revision Accepted 2, February 2009)

\section{ABSTRACT}

A total of 38 water samples were obtained from the dental unit water lines in three(3) hospital/clinics within Zaria, Nigeria viz: The Kaduna State Dental Clinic, Tudun Wada, University Health Services (Sick Bay), A.B.U. Zaria, Ahmadu Bello University Teaching Hospital, Shika, Nigeria and assessed for true and opportunistic pathogens. Sixteen (16) bacterial isolates consisting of five isolates of Pseudomonas aeruginosa and 11 isolates of Klebsiella pneumoniae were recovered. The antibiotic susceptibility profile of $K$. pneumoniae showed that it was susceptible to gentamicin and nalidixic acid but resistant to tetracycline, streptomycin ampicillin, cotrimoxazole, colistin and nitrofuratoin. Ps.aeruginosa was susceptible to gentamicin and colistin and resistant to streptomycin, ampicillin, nalidixic acid, cotrimoxazole and nitrofuratoin. These true and opportunistic pathogens may pose a health risk to the immuno- comprised patients visiting the dental clinic for surgery and other dental procedures.

\section{KEY WORDS: Antibacterial Susceptibility, Biofilm, Dental Unit Water Lines, Pseudomonas aeruginosa, Klebsiella pneumoniae,}

\section{INTRODUCTION}

Dental unit water lines (DUWLs) may be heavily contaminated with microorganisms. These organisms may be environmental organisms such as Alcaligenes denitrificans, Moraxella $\mathrm{sp}$ and Caulobacter $\mathrm{sp}$ or opportunistic and true human pathogens such as Pseudomonas aeruginosa, Klebsiella pneumoniae, Mycobacterium sp (Williams et al., 1996; Pankhurst et al., 1998; Walker et al., 2000; Franco et al., 2006).

Opportunistic pathogens may account for more than $30 \%$ of the total bacterial population in water distribution systems (Barbeau et al., 1996). Certain types of Gramnegative bacteria can persist in water and multiply actively in aqueous environments associated with some medical equipment such as the dental hand pieces. This can lead to accumulation of large numbers of Gramnegative bacteria which can directly or indirectly affect patients by causing septicaemia, abscesses and endotoxemia (Favero et al., 1992; Lonnemann et al., 1992).

The laminar flow of DUWLs encourages maximum flow at the centre and minimal flow at the periphery. This results in formation of biofilms by many bacteria on the inner surface of the tubing (Douglas and van Nourt, 1993; Fayle and Pullard, 1996).

Organisms in biofilms are derived from incoming mains water supply. Bacteria can be released from these biofilms slowly into DUWLs. During dental procedures, these organisms are sprayed in aerosols arising from the low or high hand speed device attached to the dentist's chair. Many tasks performed in dentistry can produce aerosols. Many organisms particularly bacteria can produce fatal pneumonias in immunocompromised individuals (Franco et al., 2005).
Against this background information, this study was undertaken to ascertain the possible health risks to which the unknowing public may be exposed to. Moreover, no records of such studies in Northern Nigeria are known to us.

\subsection{MATERIALS AND METHODS}

\subsection{Sample collection}

Thirty-eight dental unit water samples were collected in sterile bottles that were dechlorinated with sodium thiosulphite $\left(\mathrm{Na}_{2} \mathrm{SO}_{3}\right)$. These water samples were obtained from three different hospitals within Zaria, Nigeria; The Kaduna State Dental Clinic, Tudun Wada; Ahmadu Bello University (A.B.U) Teaching Hospital, Shika, Nigeria; and University Health Services (Sick Bay), A.B.U. Zaria, Nigeria.

\subsection{ANTIBIOTIC DISCS AND MEDIA USED}

Sterile standard Oxoid commercial antibiotic sensitivity disks used were Gentamicin $(10 \mu \mathrm{g})$, Streptomycin $(10 \mu \mathrm{g}), \quad$ Colistin $(25 \mu \mathrm{g}), \quad$ Cotrimoxazole $(25 \mu \mathrm{g})$, Ampicillin $(10 \mu \mathrm{g})$, Tetracycline $(30 \mu \mathrm{g})$, Nalidixic acid $(200 \mu \mathrm{g})$ and Nitrofuratoin $(200 \mu \mathrm{g})$.

The media used were: cetrimide agar, blood agar, Mueller-Hinton agar, Mueller-broth, Nutrient agar.

\subsection{ISOLATION OF MICROORGANISMS}

Pre-enrichment of the water samples was done by introducing $1 \mathrm{ml}$ of water sample into $5 \mathrm{ml}$ of MuellerHinton broth and the tubes were incubated at $37^{\circ} \mathrm{C}$ for $18 \mathrm{~h}$. A sterile pipette was used to deliver $0.25 \mathrm{mls}$ of the overnight broth culture into blood agar and cetrimide

H. I. Inabo, Department of Microbiology, Ahmadu Bello University, Zaria

D. O. Toryila, Department of Microbiology, Ahmadu Bello University, Zaria

F. A. Anthony, Department of Microbiology, Ahmadu Bello University, Zaria 
agar. The inoculum was spread with a sterile bent glass rod. All inoculated plates were incubated at $37^{\circ} \mathrm{C}$ for 24 h. Cultures were purified, and thereafter stored on nutrient agar slants.

\subsection{BIOCHEMICAL IDENTIFICATION OF BACTERIAL ISOLATES}

Specific biochemical tests for the true and opportunistic pathogens were done according to Barrow and Feltham (1974).

\subsection{ANTIBACTERIAL SUSCEPTIBILITY TEST}

The Kirby-Bauer method (Clinical Laboratory Institute Standards. (CLIS), (2005) was used. MuellerHinton Agar (MHA) was prepared according to manufacturer's instructions. Sterile swab sticks were used to spread- inoculate agar plates with the standardized suspension of the isolates $(0.5$ MacFarland). Using a sterile pair of forceps, antibiotic discs were evenly placed on the inoculated plates. The plates were incubated at $37^{\circ} \mathrm{C}$ for $18-24 \mathrm{~h}$ after which zones of growth inhibition were observed and their diameters measured with a metric rule. The results were classified as resistant, intermediate and susceptible according to the interpretative chart of the National Committee for Clinical Laboratory Institute Standards (CLIS, 2005).

\section{RESULTS}

Table 1 shows the bacterial isolates recovered from the three dental unit water lines and the biochemical identification. Out of the 16 isolates, five were identified as Pseudomonas aeruginosa and 11 as $K$. pneumoniae. There were six (6) K. pneumoniae isolates and no $P$. aeruginosa detected in the water samples obtained from the dental unit water lines in Sick bay,UHS, ABU, Zaria, Nigeria. The antibiotic susceptibility profiles of the isolates are presented in Table 2. K. pneumoniae was susceptible to gentamicin and colistin while P.aeruginosa was susceptible to gentamicin and nalidixic acid only.

Table 1: Cultural and biochemical characterisation of the bacterial pathogens isolated from the three dental unit water lines

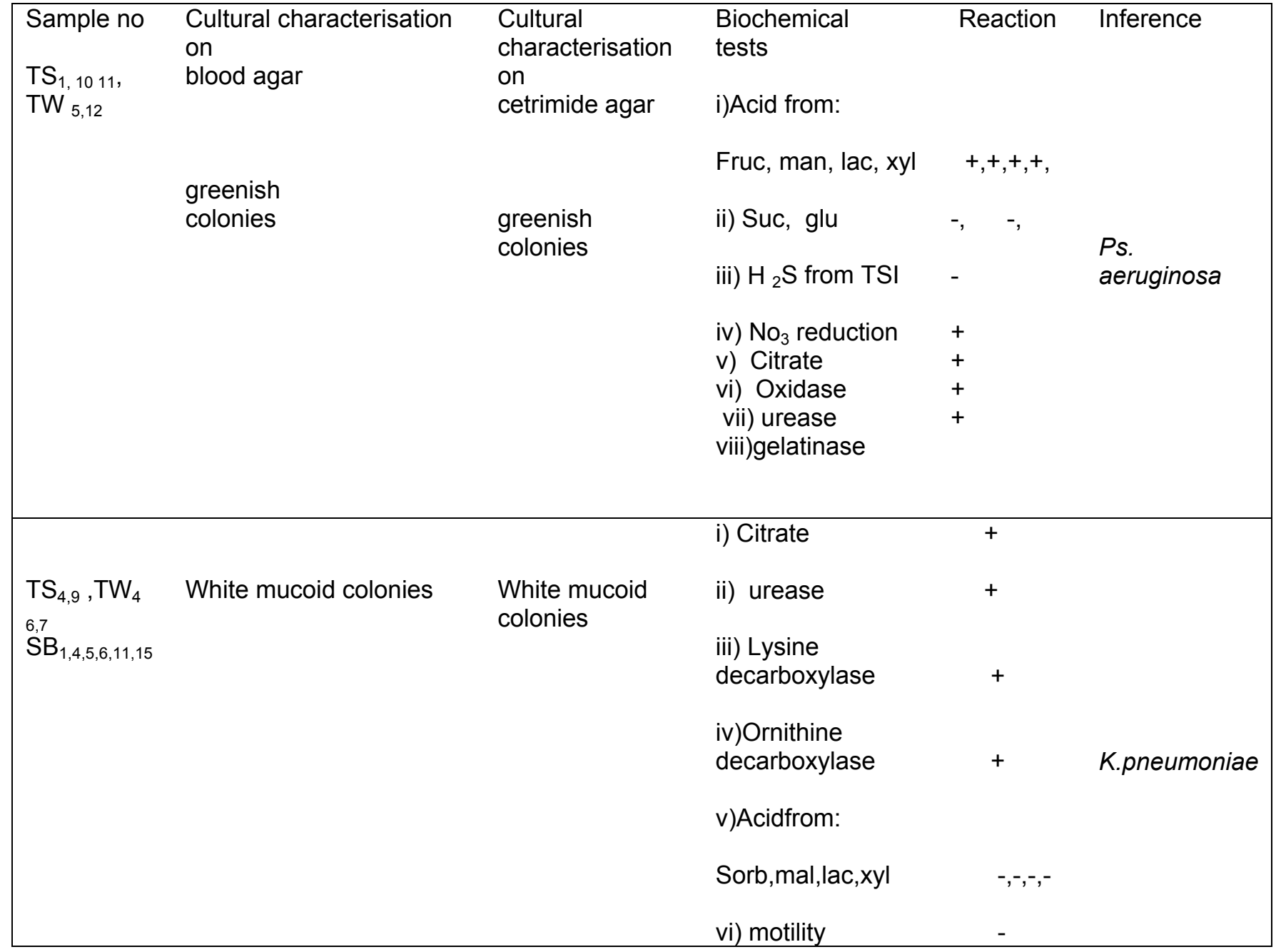

Key: TS= Water samples from ABUTH Shika, Nigeria, TW=Water samples from Dental Clinic Tudunwada, Zaria, Nigeria $\mathrm{SB}=$ Water samples from Sick Bay, UHS, ABU, Zaria, Nigeria suc=sucrose, Fruc,=Fructose, man,=mannose, lac=lactose, $x y l=x y l o s e$ Sorb=Sorbitol, mal=maltose, man=mannose 
Table 2: Susceptibility profiles of klebsiella pneumoniae and pseudomonas aeruginosa

\begin{tabular}{|c|c|c|}
\hline Antibiotic/ disc potency & $\begin{array}{l}\text { Pseudomonas } \\
\text { aeruginosa }\end{array}$ & Klebsiella pneumoniae \\
\hline Gentamicin $(10 \mu \mathrm{g})$ & $+(18 \mathrm{~mm})$ & $+(21 \mathrm{~mm})$ \\
\hline Ampicillin $(10 \mu \mathrm{g})$ & - & - \\
\hline Colistin $(25 \mu \mathrm{g})$ & $+(14 \mathrm{~mm})$ & - \\
\hline Tetracycline $(30 \mu \mathrm{g})$ & - & - \\
\hline Streptomycin $(10 \mu \mathrm{g})$ & - & $+(16 \mathrm{~mm})$ \\
\hline Nalidixic acid $(30 \mu \mathrm{g})$ & - & - \\
\hline Cotrimoxazole $(25 \mu \mathrm{g})$ & - & - \\
\hline Nitrofurantoin $(200 \mu \mathrm{g})$ & - & \\
\hline
\end{tabular}

$$
\begin{aligned}
\text { Key: } \quad \text { + } & =\text { susceptible } \\
& -=\text { resistant }
\end{aligned}
$$

\section{DISCUSSION}

Pseudomonas aeruginosa and Klebsiella pneumoniae were the opportunistic pathogens isolated from the water supply in the dental units of hospitals used in this study.

Sixteen bacterial isolates consisting of 11 isolates of K.pneumoniae and five isolates of $P$ s.aeruginosa were recovered. These two organisms are likely to cause pneumonia and/or bacteriemia in immunocompromised subjects. Water delivered through dental handpieces does not meet potable water standards because it has much higher counts as seen in this study. The reason is the high area to volume of small-bore water -lines which offers a lot of surface area on which microorganisms can settle and form biofilms (Franco et al., 2005). The American Dental Association (ADA) states that water used in dental units should be less or equal to $200 \mathrm{cfu} / \mathrm{ml}$ while the European Union has drinking water standard set at $100 \mathrm{cfu} / \mathrm{ml}$. These values are equivalent to WHO standards for dental unit water and drinking water respectively.

The water samples analysed had colonies Too Numerous To Count (TNTC/ml) which exceeded the ADA and EU standards for dental unit water. Fulford et al (2004) found counts that exceeded the ADA limit of $200 \mathrm{cfu} / \mathrm{ml}$.

The slow and quiescent nature of water in DUWLs encourages the formation of biofilms. These biofilms may adhere to the inner lining of the tubes of the dental unit lines. Tuttlebee et al (2002) showed that biofilms can be shed on a continuous basis into DUWLs and these organisms may be sprayed into the patient's mouth during dental surgery. $P$. aeruginosa is a known nosocomial pathogen and can colonize wounds and establish infections such as oral abscesses dental caries and wound infections (Anaissie, 2002; Rossolii and Mantengoli, 2005).

Predisposing factors such as Diabetes mellitus, immunoglobulin deficiency states, steroid therapy and surgery may be responsible for nosocomial infections by $P$.aeruginosa. Sterile water supplies have been recommended for surgical procedures (Parkhurst and Johnson, 1998). Ps.aeruginosa derived from Dental Unit Water Lines (DUWLs) is the only opportunistic Gramnegative pathogen that has been implicated in causing infection and is a marker of the presence of opportunistic pathogens (Walker et al., 2000).
P.aeruginosa strains were resistant to many antimicrobial agents including the older quinolones like nalidixic acid, tetracycline,ampicillin, among others. All the strains were multiresistant with a Multiple Antibiotic Resistance (MAR) index greater than 0.2. This means that the organisms must have been derived from an environment where antibiotics are used without prescription (Paul et al., 1997).

The presence of a number of active multidrug efflux systems are known to contribute to the intrinsic resistance or reduced susceptibility of this species to several antimicrobial agents (Poole, 2004). Resistance to ampicillin could be due to the presence of AmpC chromosomal $\beta$-lactamases (Livermore, 1995).

The most important anti-pseudomonal agents include some aminoglycosides( of which gentamicin is an example) and all the isolates of $P$. aeruginosa were susceptible. They were susceptible to colistin- an effective but toxic anti-pseudomonal drug (Giamarellou, 2002)

There are various approaches to risk reduction to both the patient and the dental surgeons. These include the use of anti-retraction valves and retrograde aspiration of oral fluids (Beierle, 1998), filtration (Parkhurst and Johnson, 1998), flushing, use of biocides, chlorination, autoclavable systems, use of peroxide, ozone and ultra violet light (Parkhurst and Johnson, 1998).

\section{REFERENCES}

Anaissie, E. J; Penzak, S. R; Dignani, M. C. |., 2002. The Hospital water supply as a source of nosocomial infections. Archives of Internal Medicine. 162, (13):1483-1492

Beierle, J. W., 1993.Dental operatory water lines. J. Cal. Dent. Assoc. 21:13-15

Barrow, G. I. and Feltham, R. K. A., 1974.Cowan and Steel's Manual for the identification of medical bacteria. Cambridge University Press.

Clinical Laboratory Institue Standards. (CLIS), 2005. Performance Standards for Antimicrobial susceptibility. $15^{\text {th }}$ supplement (CLIS document. M100-S15). 25. Wayne, P. A. 
Douglas, C. W. I. and Van Nourt, R., 1993. Control of bacteria in dental water supplies. Brit. Dental Journal. 174:167-174

Fayle, S.A. and Pollard, M. A., 1996.Decontamination of dental unit water systems: a review of current recommendations. Brit. Dental Journal. 181:369-372.

Favero M. S; Carson, L. A; Bond, W. W. and Petersen, N. J., 1992.Dialysis-associated infections. In Hospital infections, ( Eds. Bennett, J. Y., Brachman, P. S. and Sanford, J. P). Little Brown, Boston. pp. 375-403.

Franco, F. F. S; Spratt, D; Leao, J. C. and Porter, S. R., 2005. Biofilm formation and control in dental unit waterlines. Biofilms. 2:9-17.

Fulford, M. R; Walker, J. T. Martin, M. V. and Marsh, P. D., 2004. Total viable counts, ATP and endotoxin levels as potential markers of microbial contamination of dental unit water systems. Brit.Dental Journal. 196:157-159.

Giamarellou, H., 2002. Prescribing guidelines for Pseudomonas infections. J. Am. Chemother.49:229-333.

Livermore, D. M., 1995. $\beta$-lactamases in laboratory and clinical resistance. Clin. Microbiol. Rev. 8:557584.

Lonnemann, G., Behme, T. C. and Lenzer, B., 1992. Permeability of dialyzer membranes to TNF- $\alpha$ inducing substances derived from water bacteria. Kidney. Int. 42:61-68.

Paul, S., Beezbarauch, R. L., Roy, M. K., Chosh, A. C., 1997. Multiple Antibiotic Resistance (MAR) index and its reversion in Ps.aeruginosa. Letters in Appl. Microbiol. 24:169-171.

Pankhurst, C. L. and Johnson, N. W., 1998. Microbial contamination of dental waterlines: the scientific argument. Int. Dent. J. 48:359-368.

Rossolini, G. M. and Mantengoli, E., 2005.Treatment and control of severe infections caused by multiresistant Ps.aeruginosa.Clinical Microbiol. Infect. 11(Suppl.4): 7-32.

Tuttlebee, C. M; O'Donnell, M. J; Keane, C. T; Russell, R. J; Sullivian, D. J; Falkiner, F. and Coleman, D. C., 2002. Effective control of dental chair unit waterline biofilm and marked reduction of bacterial contamination of output water using two peroxide based disinfectants. J. Hosp. Infect. 52:192-205.

Walker, J. T; Bradshaw, D. J; Bennett, A. M; Fulford, M. R; Martin, M. V. and Marsh, P. P., 2000. Microbial biofilm formation and contamination of dental unit water systems in general dental practice. Appl. Environ. Microbiol. 66 (8):3363-3367.

Williams, H. N; Paszko-Kolwa, C; Shahamat, M; Palmer, C; Pettis, C. and Kelly, J., 1996. Molecular Technology reveal high prevalence of Legionella spp in dental units. J. of the American Dental Association.127, 1188-1193. 